\title{
Revitalizing Irrigation Systems for Food Security: Vision and Approaches in Nepal Irrigation Systems
}

\author{
Prachanda Pradhan
}

Prachanda Pradhan

\begin{abstract}
By 2050, Asia will have to face the challenge of feeding 1.5 billion extra populations. Similarly, the population of Nepal, 26 million in 2011, will also be double by 2050. Food demand will be increasing corresponding to the increase of the population. Nepal's irrigation sector must first be revitalized to unlock its potential by introducing innovative practices and changing the ways it is governed and managed. Irrigated agriculture holds great potentiality to meet the development challenges and key to increased agriculture production to feed the growing population of Nepal. Besides, increasing the agriculture production, irrigation helps promote Green Revolution, contributes for poverty alleviation, and helps promote rural growth, and food security among people. Dilapidated irrigation systems affects on all these fronts of development issues. It is, therefore, necessary to revitalize the irrigation sector to feed growing population, to ensure livelihood and poverty alleviation and maximize the benefit of available natural resources like water to get more production from limited land availability.

Hence, the revitalizing irrigation systems to meet the food demands of the future are to be considered in an integrated manner consisting infrastructure rehabilitation, investment to raise yield productivity from irrigated land and promotion of appropriate institutions and innovative management modes. There are different agencies that influence the policy and implementation of irrigation sector of Nepal. The central agency is necessary for planning, investment, monitoring, and evaluation of the sector in the larger context. At present, one feels the absence of such central agency which overlooks the overall irrigation sector in compassing all sizes and types and technologies as the national resources.
\end{abstract}

Key words: Revitalization, infrastructure improvement, agriculture productivity, governance modes, irrigated land loss, Nepal.

\section{Logic and Rational for Revitalizing Irrigation Systems}

The population is increasing both in Asia, and Nepal 1 as well. By 2050, Asia will have to face the challenge of feeding 1.5 billion extra populations (IWMI/FAO 2009). Similarly, the population of Nepal will be almost double by 2050. ${ }^{1}$ The preliminary census result of 2011 reports that the population of Nepal is 26.62 million excluding absentee population of 3.0 millions. The population growth rate is estimated to be $1.40 \%$ (Himalayan Times 2011). Nepal has to prepare to feed 57 million populations by 2050. It is estimated that Nepal has 2.7 million hectare potential agriculture land. ${ }^{2}$ Out of that, only 1.7 million hectares are considered potential for irrigated agriculture. Hence, increasing the agriculture production both from rain-fed and irrigated agriculture is a big challenge. However, the potential of substantial increase in the rain-fed agriculture is limited so the remarkable potential to meet the challenge of feeding extra population has to come from irrigated agriculture. The irrigation sector must first be revitalized to unlock its potential by introducing innovative practices and changing the ways it is governed and managed (IWMI/ FAO 2009).

Only the limited percentage out of total land area of Nepal is suitable for irrigated agriculture. Irrigated agriculture holds great potentiality to meet the development challenges and key to increased agriculture production to feed the growing population of Nepal. Besides, increasing the agriculture production, irrigation helps promote Green Revolution, contributes for poverty alleviation and helps promote rural growth, and food security among people. Dilapidated irrigation systems affects on all these fronts of development issues. In order to meet these challenges, the important question is: how can irrigation sector be revitalized? It is, therefore, necessary to revitalize the irrigation sector to feed growing population, to ensure livelihood and poverty alleviation and maximize the benefit of available natural resources like water to get more production from limited land availability. It is estimated in 1980's that extra 850,000 ha of land need to be brought under irrigation for the fulfillment of the basic need by the end of the century. In late 1980's, the World Bank estimated that in order to maintain the present rate of food consumption, Nepal needs to bring an additional 35, ooo ha of land under irrigation each year to keep up with the population growth (Pradhan 1989a).

The existing irrigation schemes of Nepal are now getting old and they require to be improved and modernized to raise food productivity from irrigated agriculture. It is often found that state built and managed irrigation systems can be made better performed, so they need to be revitalized (Facon 2005). Similarly, farmer managed irrigation systems (FMISs) in Nepal also have greater potentiality for increasing agriculture productivity (Yoder and Pradhan 2005). Hence, the revitalizing irrigation systems to meet the food demands of the future are to be considered in an integrated manner consisting infrastructure rehabilitation, investment to raise yield productivity from irrigated land and promotion of appropriate institutions and innovative management modes.

\section{Policy and Strategic Framework for Irrigation Development in the Context of Overall Population Growth and Water Management in Nepal}

The Government of Nepal (GON) attempted to address the issues of increasing the performance and potentialities of irrigation sector through the National Water Resources Strategy (NWRS) initiated in 2002 (WECS 2002). It 
defined short-to long-term institutional and physical targets and activities to be undertaken within Integrated Water Resources Management approach (IWRMP) including irrigation sector.

\section{Place of Irrigation Development in Water Resources Strategy of Nepal}

Besides other Water Sector Issues, the strategy document highlights Irrigation Issues as follows:

- reorientation of supply-driven approach,

- poor performance of irrigation systems,

- lack of effective implementation of Agriculture Perspective Plan (APP),

- farmers' dependency syndromes and sustainability,

- problems of river management,

- weak institutional capability,

- symbiotic relationship between agriculture and irrigation (weak linkages), and

- $\quad$ strengthening of WUAs (Water User Associations).

\section{Water Sector Objectives}

Water resource development, like other national development agenda, should aim to contribute to improving the quality of life. Besides other objectives, the objective is to increase agricultural production and productivity, ensuring food security of the nation is prominently highlighted.

Water Resources Strategy outputs will contribute to this goal through the achievement of short, medium and long-term purposes. These purposes have been defined as follows:

- Short-Term (5 Year) Purpose: Implementation of the comprehensive Water Resources Strategy provides tangible benefits to people in line with basic needs fulfillment, supported and managed by capable institutions of all stakeholders.

- Medium-Term (15 Year) Purpose: Water Resources Strategy is operationalized to provide substantial benefits to people for basic needs fulfillment as well as other increased benefits related to sustainable water use.

- Long-Term (25 year) Purpose: Benefits from water resources are maximized in a sustainable manner.

To achieve these purposes, the Water Resources Strategy has defined ten strategic outputs. One of the specific outputs of the irrigation sector is to make: "Appropriate and efficient irrigation available to support optimal, sustainable use of irrigable land."

\section{National Water Plan (NWP), 2005}

The National Water Plan (NWP), 2005 was prepared in order to implement the provisions of the Water Resources Development Strategy approved by the government in 2002. It guides stakeholders to implement and manage resources and water related services including irrigation services in an integrated manner. The NWP recommends the short-term, medium-term and long-term program and project planning along with investment projection and institutional reorganization (Gurung 2007; Dhungel 2007).

\section{Irrigation Policy and Agriculture Policy}

The Agriculture sector and the irrigation sector as a whole, with the collaborative effort of both public and private entities, have to respond to translate those short-term, medium-term and long-term objectives of the National Water Plan. Agriculture Policy proposes to implement the Agriculture Perspective Plan (APP) by adopting more effective, liberal and market-oriented economic policies in the agriculture sector by promoting active private sector participation in agriculture inputs like (a) chemical fertilizer, (b) shallow tube wells and (c) micro-credits along with improvements in agriculture inputs, policy reforms and institutional restructuring.

\section{Irrigated Agriculture Development Strategy}

One of the issues to address the periodic plans is the preparation of district/ river basin-based irrigated agriculture development strategy. The District Irrigated Agriculture Development Strategy (DIADS) as a tool for planning and selection of district level agriculture strategy was proposed, but the exercise on DIADS could not take place. This exercise aims at getting the information of natural resources of the district for agriculture and irrigation planning.

\section{Irrigation Institutions}

It occupies substantial share of annual investment in the national budget. Along with the World Bank (WB), Asian Development Bank (ADB) and other donors, the Government of Nepal (GON) has substantial share of investment in irrigation sector of Nepal. This is an important driver to promote irrigated agriculture, which occupies important place in domestic production as well as rural employment in Nepal.

There are different agencies, which influence the irrigation sector of Nepal. The National Planning Commission (NPC), Ministry of Irrigation (MOI), Ministry of Finance (MOF), and Water and Energy Commission Secretariat (WECS) are responsible for initiating appropriate policy on irrigation development in Nepal. Recently, the GON has shifted towards mega-irrigation projects and inter-basin water transfer projects as well. However, the micro-irrigation like non-conventional irrigation systems, small and medium irrigation systems also contribute to ensure food security. These policy making bodies have to take comprehensive approach incorporating all these resources (mega, medium and micro systems) to decide on the investment, choice of appropriate technology, water right issue on different water sectors, allocation of water resources to different sectors keeping in view of integrated water resources management program, direction towards management types and governance modes, etc.

Irrigation development and management is undertaken by different agencies of the government and private sector in Nepal. The institutions that are contributing for irrigation development in Nepal are: (a) Department of Irrigation (DOI), (b) Department of Agriculture (DOA), (c) Ministry of Local Development (MOLD) through DOLIDAR (Department of Local Infrastructure Development and Agricultural Roads), (d) Ground Water Resources Development Board (GWRDB), (e) ADB/Nepal 
(f) farmers' community, and private sector organizations (e.g., NGOs such as International Development Enterprises (IDE), SAPPROS/Nepal (SupportActivities for Poor Producers of Nepal), etc.). Similarly, the educational and research institutes like agriculture and engineering colleges and the National Agriculture Research Council (NARC) are also important players to contribute for the better performance of irrigated agriculture. Among these different agencies involved in irrigation sector development, the DOI has a major share in promoting and managing the irrigation systems in Nepal. The DOI is involved in multi-facet aspects of irrigation development. Prominent among them are surface irrigation system of all sizes above 25 ha (small, medium and large), ground water development by shallow tube well (STW) and deep tube well (DTW), and lift irrigation systems.

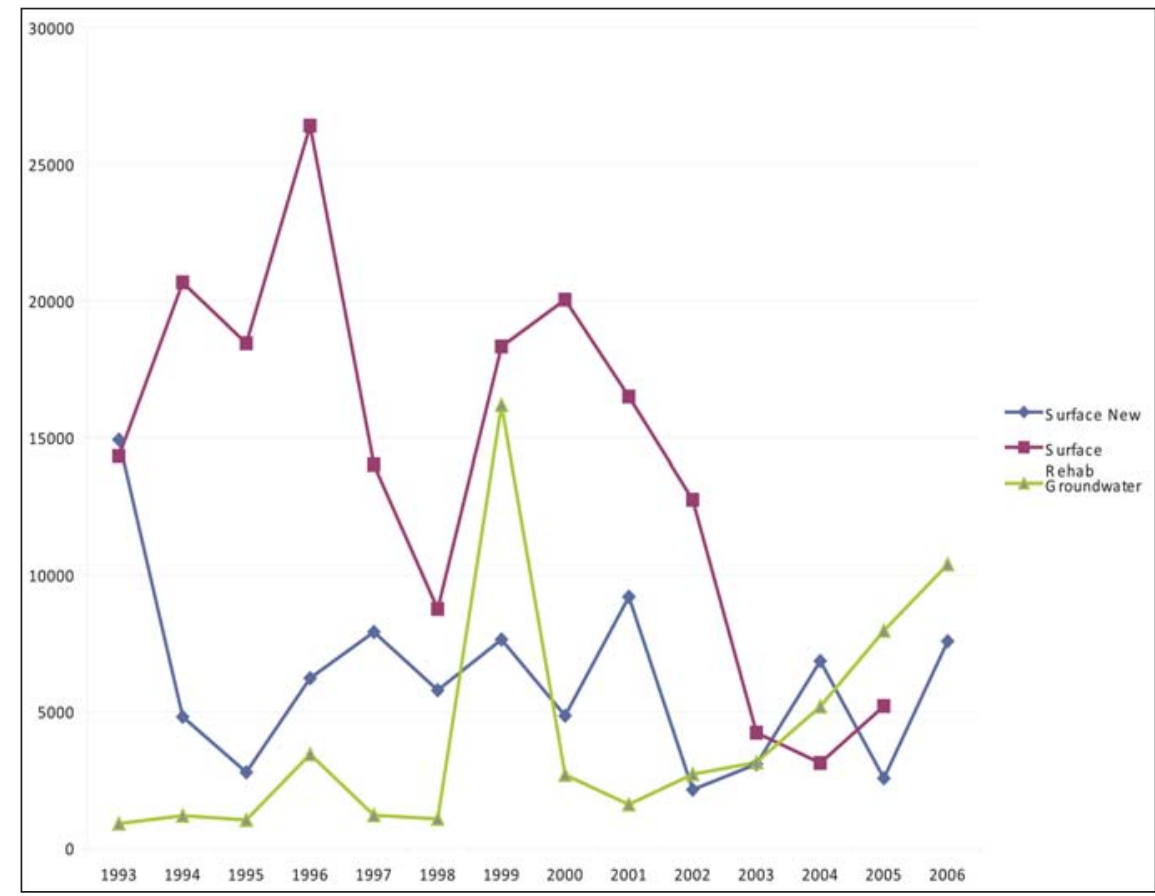

Figure 1. Irrigation Development from 1993-2006 (source: Gurung 2007).

\section{Focus on Revitalization of Irrigation Systems in Nepal}

The NWP 2005 puts a set of physical targets in irrigation sector for increased agriculture production. These targets are for round the year irrigation, increased irrigation efficiency, increased cropping intensity as well as increased irrigation facilities in the potential irrigable area.

\begin{tabular}{|l|c|c|r|}
\hline Stages & $\begin{array}{c}\text { Potential } \\
\text { Irrigable } \\
\text { Area }\end{array}$ & $\begin{array}{c}\text { \% of Irrigated } \\
\text { Area }\end{array}$ & $\begin{array}{c}\text { \% of Round } \\
\text { the Year } \\
\text { Irrigation }\end{array}$ \\
\hline Stage I & $1,700,000$ & $1,207,000(79 \%)$ & $586,000(49 \%)$ \\
\hline Stage II & $1,700,000$ & $1,445,000(85 \%)$ & $924,000(64 \%)$ \\
\hline Stage III & $1,700,000$ & $1,649,000(97 \%)$ & $1,104,000(67 \%)$ \\
\hline
\end{tabular}

Table 1. Target for Irrigation Development in NWP 2005 through its Different Stages (source: WECS 2005).

Taking the irrigation facility base as 1.2 million ha in 2011, by 2027 (within 15 years) 442,000 ha irrigated area is to be added if $97 \%$ of irrigable area is to provide irrigation facility. This will require adding about 30,000 ha irrigation facility each year for next 15 years according to NWP of Nepal. On top of that, effort is to be made to increase cropping intensity, agriculture productivity and irrigation system efficiency.

For 14 years from 1992-2006, there has been in an average of $6,703 \mathrm{ha} /$ year increase in surface irrigation, 13,052 ha rehabilitation/year and 3,903 ha/year in ground water. The total new area addition in irrigation sector is only 10,606 ha/year. During rehabilitation, very limited new area will be added. Ground water utilization has shown a positive trend to increase extra-irrigated land.

The trend between the target and achievement among the projects also indicates the non-achievement of the targets. The example of IWRMP (2007-2013) shows the revision of target and achievements in surface irrigation of component A. The original target was 26,392 ha, which is revised by the mid-term review to 15,141 ha. The achievement in the third year of project implementation is reported to be 2,200 ha by July 2011 (as shown in Figure 2, based on an interview with Mr. Kunjan Shrestha, IWRMP, October 9, 2011). It is expected that by the end of the project period, the revised target will be met. Similarly, CMIASP has also revised its original target from 34,000 ha to 13,700 ha and physical achievement so far is 3,000 ha. It is expected to meet the revised target by the end of the project period (see Figure 3, from a discussion with Navin Mangal Joshi, Project Director, CMIASP, October 9, 2011). The gap between target and achievement is shown in Figures 2 and 3.

In order to meet the above mentioned targets to increase agriculture productivity and irrigation facility, revitalization in the irrigation systems is to be undertaken.

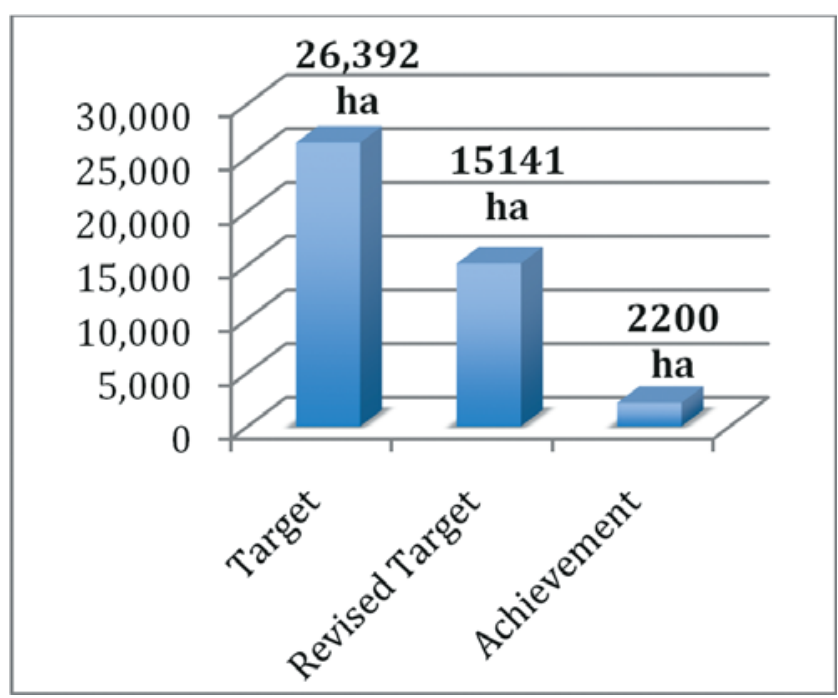

Figure 2. CMIASP Target and Achievement. 


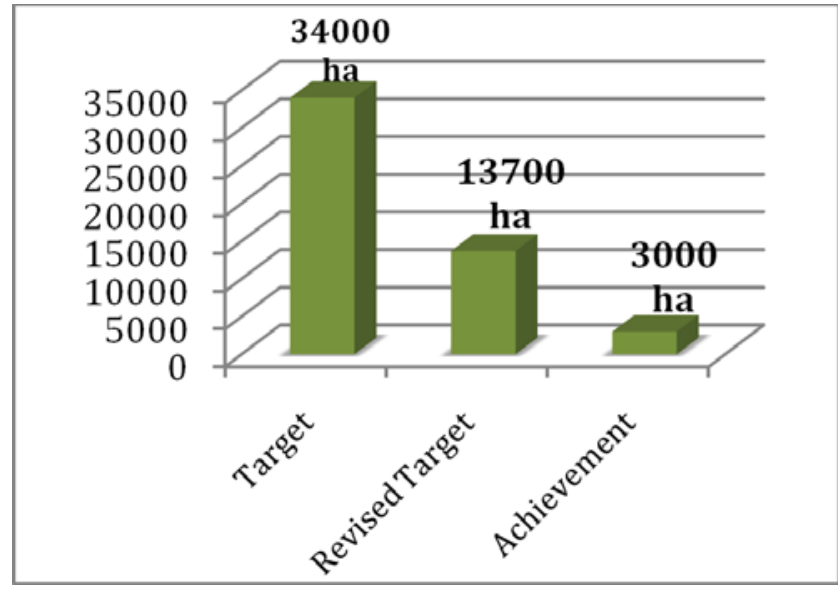

Figure 3. IWRMP Target and Achievement.

The revitalization of irrigation systems should include (a) physical improvement, (b) increased irrigated agriculture productivity and (c) institutional reforms. Case studies of Irrigation Management Transfer (IMT), FMIS of different sizes will be presented. It is important to mention here regarding the annual loss of irrigated land caused by flood, river bank erosion, land slides, unfriendly weather condition affecting the destruction of the crops, housing developments in the prime lands and sand mining in the rivers, etc. However, there is no comprehensive record which can help make a comparison of the newly added irrigated land with that of land loss by natural disaster and unplanned man made developments.

\section{Case Study of Improvement of Agency Managed Irrigation Systems (AMISs) through Irrigation Management Transfer (IMT) Program}

It is reported that agency managed irrigation systems (AMISs) have poor performance and there are potentialities for their performance improvement through appropriate type of Irrigation Management Transfer (IMT). IMT means a process in which some functions and responsibilities of management, formally exercised by a state agency, are transferred to an organization of the users of the irrigation system. Appropriate IMT with well defined objectives to the users address the issue of increasing agriculture productivity and better irrigation infrastructure performance. Hence, IMT attempts to address the problem of below capacity performance, poor O\&M, negligible cost recovery, inadequate funds for the management of irrigation systems and finally the problem to increase agriculture production. IMT is one of the important methods of revitalization of irrigation systems.

It is recognized that there is scope for performance improvement of AMISs by improving the service delivery through responsibility division between the agency personnel of DOI and water user associations (WUAs), and support to strengthen the WUAs. The agency needs to consider that IMT is not only physical improvement; it includes the institutional reforms and agriculture productivity improvement. These components have to go together. One of the important features of IMT in the new approach adopted in Nepal is the signing of agreement between the farmers group and the agency with the responsibility division between DOI taking charge of maintenance and management of headwork and main canal, and WUA taking charge below the main canal. The agreement thus signed between these two parties includes the provision of penalty for failure to comply the terms of agreement by either party.

\section{Case Study of Modernization of Large Scale Farmer Managed Irrigation Systems (FIMIS)}

It is estimated that 70\% irrigated area in Nepal fall in the category of farmer managed irrigation systems (FMISs) (Pradhan 1989b)). FMISs have greater potentiality for management improvement and increased agriculture production. Recognizing the potential for improvement of these systems, the Nepal government has mobilized funds from donor agencies for improvement of these systems.

Two interesting Nepal examples are presented here: the farmer managed Rani, Jamara and Kulariya Irrigation Systems (RJKIS) of Kailali District and the Rajapur FMIS of Bardiya District. Both of them are each of about 15,000 ha and over a hundred years old systems. Both of them have the Karnali River, one of the big river systems, as the source of water of RJKIS is the Karnali and that of Rajapur is the Geruwa, a bifurcation of the Karnali River. The water flow fluctuation in the river ranges from $173 \mathrm{~m}^{3} / \mathrm{s}$ during dry season to $16,000 \mathrm{~m}^{3} / \mathrm{s}$ during monsoon (HMD 2001). The farmers have organized themselves to get irrigation water under the huge fluctuation of river water. Within those 15,000 ha, there are several systems, but the command area is physically contiguous.

The Rajapur Irrigation System has potentiality for increased agriculture production. The objectives of the rehabilitation of Rajapur Irrigation System are: (a) increasing agriculture production and farm income, (b) protection of land erosion through flood, (c) reduction of environmental degradation through less reliance on forest products for repair of irrigation systems, and (d) strengthening institutional base and technical capability of WUA members.

The loan covenant of the Asian Development Bank (ADB/Manila) stipulates that the farmers will get timely access to necessary agriculture support services. The completion report of $\mathrm{ADB}$ states that the absence of integrating these two elements (agriculture and irrigation) with the project has hindered farmers taking full advantage of improved irrigation facilities to increase agriculture production (ADB 2003).

Drawing lesson from the Rajapur Irrigation Rehabilitation Project, Rani, Jamara and Kulariya FMIS of about 15,000 ha command area of Kailali district located on the opposite side of Rajapur Irrigation System, the modernization of this system is designed in two phases with four components (WB 2011). They are: (a) physical rehabilitation called scheme modernization, (b) strengthening water users associations, (c) agriculture production support, and (d) project management.

They have great potentiality for increasing agriculture production. Both these systems are flood irrigation types, not having any water control structures for proper water distribution in the command area. In the Rajapur Irrigation System as well as in the Rani, Jamara and Kulariya system at the first phase, it is proposed to have control structures at the intake point of the system. The 
stages of irrigation development can be characterized as, firstly, flood irrigation (capture the water when there is flood in the water source.) The second stage of irrigation development is the establishment of control structure at the intake point so that water flow in the system can be regulated. The third development of the irrigation system is the installation of number of control structures and field channels in the command area so that water can be made available where water is in need for crop growth. The fourth stage is the automation of the regulators to let the water flow according to the size of the command area and demand of the users. Finally, the irrigation system will be designed in such a way that water distribution will be regulated by computer programming based on the moisture requirement to the crop roots. Many irrigation systems have come to third stage development in Nepal.

\section{Case Study of Medium Size FMIS}

FMISs are owned and managed by the farmers themselves. At present, about $40 \%$ of food requirement of the country come from these irrigation systems. Hence, they have an important role for food security as well their contribution to the Nepalese economy. There have been many modes of intervention in the FMIS in Nepal (Ostrom, Lam et al 2011; ADB 2006; WB 2007). IWRMP and CMIASP have the objective to improve agriculture productivity of existing small and medium size FMIS suffering from low productivity and high poverty incidence and help enhance the livelihoods of the poor men and women. These objectives shall be translated by providing improved means for WUA empowerment, improving irrigation facilities, promoting agriculture extension, targeting livelihood enhancement to build human capital of the poor and strengthening policies, plans and institutions for more responsive service delivery.

\section{Other Types of Irrigation Systems and Their Implications (by Technology- Ground Water Irrigation, Micro-irrigation, Irrigation Systems below 25 hectare)}

Other important segment of irrigation sector which is unorganized yet contributes substantially to the food security of Nepal and helps alleviate the poverty is the small irrigation systems below 25 ha, utilization of groundwater through individually owned STW, and micro-irrigation systems utilizing small local sources of water and different technologies. This sector deserves special attention to revitalize and consider this sector from the approach of physical improvement, support system for increasing agriculture production and policy and institutional arrangement and governance mode whereby users can derive benefit out of this sector. It is estimated that this sector covers thousands of hectare of agriculture land and millions of users both in plain area of Terai for STW as well as in the difficult inaccessible remote hill and mountain areas (Upadhyaya 2000; Chapagain 2000). Recently, there has been consideration of multiple use of small source of water for drinking purpose as well as for economically productive activities (Pant, Sakya and Adhikary 2006). Except for ground water utilization, there is no strong institution to promote and protect this category of irrigation systems with different technologies.

\section{Synthesis of Case Studies}

Out of those case studies, one finds that there are still potentialities to derive enormous increased agriculture productivity benefit from the revitalization of different types of irrigation systems in Nepal. With appropriate physical improvement and improved governance mode empowering the users group, the agency managed systems bring out their potentiality and improve underperformance. Similarly, appropriate physical improvement activities along with proper institutional arrangement and agriculture production promotion program would generate positive results to feed the growing population as well as meet the challenges of water scarcity. There is need to have considerations for the revitalization of small and microirrigation systems. The approaches of revitalization of this sector have to be unconventional irrigation rehabilitation and intervention program. The focus of revitalization of this sector of program has to be more of people and their way of managing natural resources within the community. The physical improvements of irrigation systems cost substantial investment. Hence, physical revitalization has to be considered from poverty alleviation, gender concern, regional balance and inclusiveness.

Increasing agriculture production is the important agenda behind the revitalization of the irrigation systems. There are tremendous potentialities of increasing agriculture production through appropriate mix of better water management and agriculture improvement technologies and market oriented agriculture production. Rice production occupies major share of irrigated agriculture. Out of 1.4 million hectare rice production area, about one million hectare has irrigated rice cultivation. Rice yield/ha is very low in the region, amounting in an average of 2.79 ton/ha (Uprety 2007). However, records of production from agriculture research farms show that there is potentiality for increasing production of 6 ton/ ha of rice. Similarly, pilot experiments of the adoption of the System of Rice Intensification (SRI) in Nepal show the yield of 6-10 ton/ha (Uprety 2007; Uphoff 2007). Other crops also have potentiality to increase yield.

The governance of irrigation management is important. The centralized management system of irrigation systems has proven that it is not conducive for better water management, resource mobilization and agriculture production. There is a big debate going on whether bureaucracy or community should be managing irrigation systems. There are even debates going on stating neither state nor private sector but the community can better manage the irrigation systems (Ostrom 1994). Therefore, revitalization of irrigation systems has to have multi-dimensional features to address resources (water), physical infrastructure (canal and other control structures) as well as placing the farmers in the driver's seat and creating appropriate governance procedures (irrigation institutions) (Ostrom, Lam et al 2011).

A central agency is necessary for planning, investment, monitoring, and evaluation of the sector in the larger context. At present, one feels the absence of such a central agency to oversee the overall irrigation sector encompassing all sizes, types and technologies as the national resource to ensure the food security. 
Prachanda Pradhan, PhD, was Professor of Public Administration in Tribhuvan University, Nepal. He is also the Patron of the Farmer Managed Irrigation Systems Promotion Trust, Nepal. He has worked as a researcher, professor and consultant in Asia, Africa and the USA for several years. He is a co-author of the book, Improving Irrigation in Asia: Sustainable Performance of Innovative Intervention in Nepal (2011, Cheltenham, UK: Edward Elgar).

Corresponding address: pradhanpp@hotmail.com

\section{Notes}

1 The preliminary result of Census of 2011 estimates the population of Nepal to be 26 million. If the growth rate is taken $1.5 \%$, it will be 47 million by 2050. If the growth rate is taken as $2 \%$, it will be 57 million by 2050 .

2 The figure given by Department of Irrigation (DOI) and Department of Agriculture (DOA) of Nepal are different. They are 2.7 million ha and 3.2 million ha respectively. For the purpose of this paper, I use the DOI figure.

\section{References}

ADB (Asian Development Bank), 2003, Project Completion Report on the Rajapur Irrigation Rehabilitation Project in Nepal, Manila: ADB.

ADB, 2006, Community Managed Irrigated Agriculture Sector Project, Project Administration Memorandum, Loan No.2192-NEP-SF, Manila: Asian Development Bank.

Chapagai, D., 2000, 'Land tenure and poverty, status and trends land systems in the hills and mountains of Nepal', in M. Baskota et al (eds.), Growth, Poverty Alleviation and Sustainable Resource Management in the Mountain Areas of South Asia, Kathmandu: International Center for Integrated Mountain Development (ICIMOD).

CAWMA (Comprehensive Assessment of Water Management in Agriculture), 2007, Water for Food, Water for Life: A Comprehensive Assessment of Water Management in Agriculture, London: Earthscan and Colombo IWMI.

Dhungel, S., 2007, 'National water plan for irrigation subsector', in Proceedings of Department of Irrigation, National Workshop on Irrigation Development and Modernization: A Road Map to New Nepal, Kathmandu: Department of Irrigation, Government of Nepal.

Facon, T., 2005, 'Asian irrigation in transition: Service orientation, institutional aspects and design, operation, infrastructure issues', in G.P. Shivakoti et al (eds.)., Asian Irrigation in Transition: Responding to Challenges, New Delhi: Sage.

Gurung, M.B., 2007, 'Revitalizing Department of Irrigation for a new Nepal', in Proceedings of Department of Irrigation, National Workshop on Irrigation Development and Modernization: A Road Map to New Nepal, Kathmandu: Department of Irrigation, Government of Nepal.

HMD, 2001, Daily Discharge Record of Station No. 280, Chisapani, Karnali River, Kathmandu: Hydrology and Metrology Department.
Himalayan Times, 2011, Daily Newspaper, September 28, 2011, Kathmandu: Nepal.

IWMI/FAO, 2009, Revitalizing Asia's Irrigation: To Sustainably Meet Tomorrow's Food Need, Colombo: IWMI/FAO (International Water Management Institute and UN Food and Agriculture Organization).

Ostrom, E., 1994, 'Neither market nor state: Governance of common pool resources in the twenty first century', IFPRI Lecture Series, Washington DC: International Food Policy Research Institute.

Ostrom, E., Wai Fung Lam, P. Pradhan and G. Shivakoti, 2011, Improving Irrigation in Asia: Sustainable Performance of an Innovative Intervention in Nepal, Cheltenham, UK: Edward Elgar.

Pant, D.S., D. Sakya and D.L. Adhikary, 2006, Multiple Use Schemes: Benefit to Stakeholders, Working Paper 114, Colombo: International Water Management Institute.

Pradhan, P., 1989a, Increasing Agriculture Production in Nepal: Role of Low cost Irrigation Development through Farmer Participation, Colombo: International Irrigation Management Institute.

Pradhan, P., 1989b, Patterns of Irrigation Organization: A Case Study of 21 Farmer Managed Irrigation Systems, Colombo: International Irrigation Management Institute

Upadhyaya, H.K., 2000, 'Sustainable poverty alleviation and mountain development in Nepal: Status, experience and strategy', in M. Baskota et al (eds.), Growth, Poverty Alleviation and Sustainable Resource Management in the Mountain Areas of South Asia, Kathmandu: International Center for Integrated Mountain Development (ICIMOD).

Uphoff, N., 2007, 'Making Farmer Managed Irrigation systems more productive and profitable with the System of Rice Intensification (SRI)', in P. Pradhan et al (eds.), Irrigation in Transition: Interacting with Internal and External Factors and Setting the Strategic Action, Kathmandu: Farmer Managed Irrigation Systems Promotion Trust.

Uprety, R., 2007, 'The System of Rice Intensification (SRI): A good alternative for increasing irrigated rice cultivation and its productivity in Nepal', in P. Pradhan et al (eds.), Irrigation in Transition: Interacting with Internal and External Factors and Setting the Strategic Action, Kathmandu: Farmer Managed Irrigation Systems Promotion Trust.

WECS, 2002, Water Resources Strategy, Nepal, Kathmandu: Government of Nepal, Water and Energy Commission Secretariat.

WECS, 2005, National Water Plan, Nepal. Kathmandu: Government of Nepal, Water and Energy Commission Secretariat.

WB, 2007, Irrigation and water Resources Management Project (IWRMP), Washington DC: The World Bank.

WB, 2011, Modernization of Rani , Jamara and Kulariya Irrigation Scheme, Washington DC: The World Bank.

Yoder, R. and P. Pradhan, 2005, 'Farmer Managed Irrigation Systems in Asia: Subsistence agriculture in transition', in G.P. Shivakoti et al (eds.)., Asian Irrigation in Transition: Responding to Challenges, New Delhi: Sage. 